affect labour such as an unfavourable cervix and induction,,$^{10}$ and found no difference in these among either height or shoe size subgroups, thus adding weight to the conclusion that the high caesarean section rates for disproportion in mothers less than $160 \mathrm{~cm}$ tall are real observations.

The longheld belief that maternal stature and shoe size have an important bearing on the outcome of labour should be modified. A well conducted trial of labour should be considered in all primigravidas with cephalic presentation irrespective of maternal height or shoe size unless obstetrically contraindicated.

We thank Drs Lees, Hulse, MacLean, and Milne, consultant obstetricians at Raigmore Hospital, Inverness, for allowing their patients to be studied; Sister Jean Campbell and Staff Midwives Linda Thomson and Hilary Munro at the antenatal clinic for recruiting the patients; Mr A A Smith, statistician, for interim analyses; Professor A A Templeton for helpful suggestions; and Mrs Irene Morrison for secretarial help.
1 Baird D. Secial factors in obstetrics. Lancet 1949; i: 1079-83

2 Bernard R.M. The shape and size of the female pelvis. Edinhurgh . Medical Joumal 1952:59:1.9.

Walker J. Prolonged pregnancy sundrome. Am 7 Obstet (jinecol 1958;76 $1231-47$.

+ Garrey M, Govan OAT, Hodge C, Callender R, eds. Obstetrics illustruted. Edinburgh: (hurchill Livingstone, 1973.

5 Donald I. Practical obstetrical problems. 5 th ed. London: Llovd-Luke, 1979.

6 Kennedy JL. Greenwald E. Correlation of shoe size and obstetric outcome Am fOhstet (ivinecol 1981;140:466-7.

7 Munice HL. Relationship of shoe size and cephalopelvic disproportion. Am. 7 Obstet (ivnecol 1982;142:931-2

8 Frame S, Merre J, Peters A, Hall D. Maternal height and shoe size as predictor of pelvic disproportion: an assessment. Br $\mathcal{F}$ Obstet Gynaecol 1985;92 $1239-45$.

9 Molov HC. Evaluation of the pelies in obstetrics. Philadelphia: Saunders, 1951. 10 Calder AA, Embrey MP, Hillier K. Extra-amniotic prostaglandin E, for the induction of labour at term. Foumal of Obstetrics and (jynaecology of the British Commonivealth 1974:81:39-46.

11 Schwart\% (iS, Kirkpatrick RH. Tovell HMM. Correlation of cephalopelvimetry to obstetrical outcome with special reference to radiologic pelvimetry to obstetrical outcome with
disproportion. Rudiologv 1956:67:856-62.

12 Mengert W'F Estimation of pelvic canacity. 7.1.11:1948:138:169-74.

13 Russel JGB. Moulding of the pelvic outlet. Foumal of Obstetrics and Gynaecologv' of the British Commonwealth 1969;76:817-20
Department of Community

Health, School of

Medicine, University of

Auckland, New Zealand, and Department of

Radiology and Coronary

Care Unit, Green Lane

Hospital, Auckland,

New Zealand

Alistair W Stewart, BSC, research officer

John Fraser, FRCR, cardiac

radiologist

Robin $M$ Norris, FRCP, honorary professor of

cardiovascular therapeutics

Robert Beaglehole, MD,

professor of community health

Correspondence to: $\mathrm{MrAW}$ Stewart, Department of

Community Health, School

of Medicine, University of

Auckland, Auckland, New

Zealand.

\title{
Changes in severity of myocardial infarction and three year survival rates after myocardial infarction in Auckland, 1966-7 and 1981-2
}

\author{
Alistair W Stewart, John Fraser, Robin M Norris, Robert Beaglehole
}

\section{Abstract}

Mortality from coronary heart disease has been declining steadily over the past 20 years in Auckland. The possibility that improved survival contributed to this decline was examined in patients who survived four weeks after myocardial infarction, changes in the severity of the disease being controlled for. Patients who had had myocardial infarction in 1966-7 (191 patients) or 1981-2 (203) were compared to determine whether three year survival rates had changed and the severity of the disease altered. With a coronary prognostic index taken as the measure of severity the 1981-2 group had significantly more severe myocardial infarctions than the 1966-7 group, but despite this the three year survival was significantly better $(86 \%$ in the $1981-2$ group $v 75 \%$ in the 1966-7 group).

These findings suggest that improved survival after myocardial infarction contributed to the decline in mortality.

\section{Introduction}

Mortality from coronary heart disease has been decreasing in New Zealand at roughly $2 \%$ a year since $1968,{ }^{\prime}$ and this could be due to a decreasing incidence of the disease or of fatal cases, or both. In Auckland during 1974-81 the rate of acute myocardial infarction did not decrease ${ }^{2}$ and one and three year survival after infarction did not show a clear improvement, ${ }^{3+}$ although the rate of sudden death from coronary causes declined steadily. ${ }^{2}$ We compared the three year survival rates after myocardial infarction in 1966-7 and 1981-2, taking into account changes in the severity of the illness over this time.

\section{Patients and methods}

1966-7-We used a subset of data from all 757 patients with acute myocardial infarction admitted to the three hospitals in Auckland between March 1966 and February 1967. ${ }^{5}$ The severity of infarction was measured as the coronary prognostic index, which is derived from the patient's age; size of the heart and state of the lung, assessed from an $x$ ray film of the chest at the time of infarction; and history of myocardial infarction." The coronary prognostic index was calculated for each of the patients at admission. We obtained information on the patients' survival to three years from their general practitioners or by other methods. ${ }^{6}$ Complete records from 1966-7 were available only on patients who were discharged from hospital. As the average time to discharge fell considerably between 1967 and 1981 the day of discharge was not a useful starting time for this study. Therefore we arbitrarily chose to study the patients who survived for four weeks after their myocardial infarction. This meant that 191 patients were studied.

1981-2 - The patients studied in 1981-2 came from a register of all patients in Auckland aged less than 70 with definite myocardial infarction according to the criteria of the World Health Organisation. ${ }^{7}$ We obtained information on the patients' survival to three years by contacting the patients, their relatives, or their general practitioner. ${ }^{+}$Information on the size of the heart and state of the lungs for estimating the coronary prognostic index was obtained by one of us (JRF), who reviewed all chest $x$ ray films taken on the day of admission to hospital. ${ }^{6}$ As the films were available only at one hospital, only patients admitted to this hospital who survived for four weeks were considered for study. This limitation resulted in the study group comprising 233 patients.

Survival rates were calculated by the Kaplan-Meier life table method, initially without regard to the coronary prognostic index, and the rates were compared by the log rank test. The chance of dying compared with a reference group was calculated by fitting a model with proportional hazards general linear regression. ${ }^{x}$

\section{Results}

Among the 233 patients with a myocardial infarction in $1981-2$, the $x$ ray film obtained at admission could not be traced for $30(13 \%)$, and hence in these patients 


\begin{tabular}{|c|c|c|c|c|}
\hline & $\begin{array}{c}1966-7 \\
(n=191)\end{array}$ & $\begin{array}{c}1981-2 \\
(\mathbf{n}=203)\end{array}$ & $\begin{array}{c}\text { Test of } \\
\text { difference }\end{array}$ & $\mathrm{p}$ Value \\
\hline No & 191 & 203 & & \\
\hline No (\%) of women & $54(28)$ & $45(22)$ & $x_{1}^{2}=1.9$ & $0 \cdot 16$ \\
\hline Mean $(S D)$ age (years) & $56 \cdot 9(8 \cdot 1)$ & $57 \cdot 3(8 \cdot 5)$ & $t_{392}=0.69$ & $0 \cdot 50$ \\
\hline No $(\%)$ with enlarged heart: & $54(28)$ & $77(38)$ & $x_{1}^{2}=5 \cdot 1$ & $0 \cdot 02$ \\
\hline Doubtful & $23(12)$ & $26(13)$ & & \\
\hline Definite & $31(16)$ & $51(25)$ & & \\
\hline No $(\%)$ with abnormalities of lung fields: & $54(28)$ & $85(42)$ & $\% \hat{1}=9 \cdot 8$ & $0 \cdot 002$ \\
\hline Venous congestion & $29(15)$ & $45(22)$ & & \\
\hline Interstitial oedema & $15(8)$ & $22(11)$ & & \\
\hline Pulmonary oedema & $10(5)$ & $18(9)$ & & \\
\hline No (\%) with past history of myocardial infarction & $44(23)$ & $63(31)$ & $\chi_{1}^{3}=3 \cdot 2$ & 0.07 \\
\hline Mean (SD) coronary prognostic index & $4 \cdot 3(3 \cdot 0)$ & $5 \cdot 4(3 \cdot 2)$ & $t_{392}=3.50$ & 0.0005 \\
\hline
\end{tabular}

the coronary prognostic index could not be calculated. These 30 patients were similar to the remaining 203 in age and three year survival, but a lower proportion of them had a history of myocardial infarction $(20 \%(6 / 30)$ $\left.v 31 \%(63 / 203) ; \chi_{1}^{2}=1 \cdot 8, p=0 \cdot 18\right)$. Of the 191 patients with a myocardial infarction in 1966-7, $31(16 \%)$ were followed up for two and a half years (because the date of follow up was the same for all patients) and so their survival rates are for only two and a half years. Of the 203 patients with a myocardial infarction in 1981-2, eight patients were lost to follow up at three years; six were known to have survived for at least 12 months and all were incorporated into the analysis as censored data points at last known time that they were alive. The reproducibility of review of the $x$ ray films was examined by repeat blind reading of 20 films. Assessments of the size of the heart agreed in all 20 cases with the initial assessment, and assessments of the lungs were identical in 17 cases.

Comparison of the 203 patients in the 1981-2 group with the 191 in the 1966-7 group showed no differences in the distribution of age or sex (table). A significantly higher proportion of the 1981-2 group, however, had both cardiac enlargement and pulmonary congestion and oedema, and a higher proportion had a history of myocardial infarction, although this was not significant. These differences resulted in a significant difference in the coronary prognostic index between the groups, with the 1981-2 group having more severe disease as measured by the index (table). Despite this the overall three year survival rate in the 1981-2 group was significantly higher than that in the 1966-7 group ( $86 \%$ in $1981-2 v 75 \%$ in $\left.1966-7 ; \chi_{1}^{2}=5 \cdot 5, \mathrm{p}=0.02\right)$. When severity of illness was incorporated into the analysis the difference was even greater $\left(\chi_{1}^{2}=11 \cdot 1\right.$, $p=0.0009)$. The three year survival rates for three categories of the coronary prognostic index-namely, an index $<3,3-8$, and $\geqslant 9$-were $88 \%, 65 \%$, and $38 \%$, respectively, in the $1966-7$ group and $97 \%, 85 \%$, and $63 \%$, respectively, in the $1981-2$ group (figure). Only 40 patients had an index $\geqslant 9$, of whom 19 died; 169 had an index of $<3$ and 185 of 3-8, the number of deaths being 13 and 41 , respectively. There were no differences in survival by sex or history of myocardial infarction.

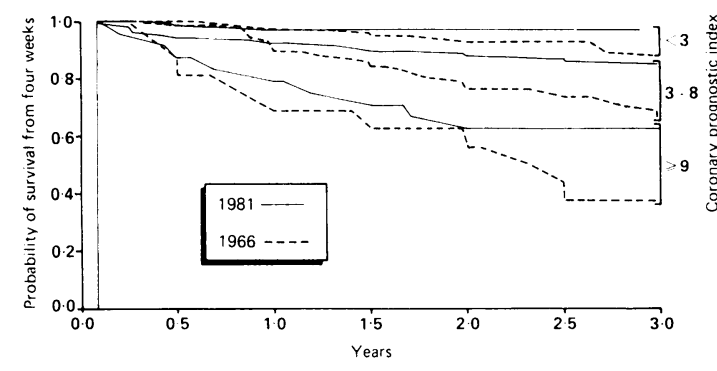

Three year survival curves for patients who survived four weeks after myocardial infarction in 1966-7 and 1981-2 categorised by coronary prognostic index
A proportional hazards general linear regression model fitted to the data gave a regression coefficient of 0.21 (SE 0.03 ) for the effect of the coronary prognostic index. This can be converted to an odds ratio showing the effect of the index. For example, compared with a patient aged under 50 with no enlargement of the heart, no abnormalities of the lung, and no history of myocardial infarction (coronary prognosis index $=0.98$ ) a patient aged 60-69 with an enlarged heart, pulmonary oedema, and a history of myocardial infarction (coronary prognostic index $=13 \cdot 2$ ) would have 13.3 ( $95 \%$ confidence interval $6 \cdot 1$ to $28 \cdot 6$ ) times the chance of dying before three years. The rate of improvement in survival between the groups in our study did not seem to differ appreciably with any of the categories of severity of infarction.

\section{Discussion}

The three year survival rates after a definite myocardial infarction in 1966-7 and 1981-2, controlling for severity of the infarction, showed an improvement for 1981-2, although the severity of infarction in the survivors at four weeks had increased. This change in severity is contrary to that which we had predicted, ${ }^{4}$ and we do not know how much of it was due to the change in the criteria defining definite infarction, in the natural course of the disease, or in the effects of changes in management.

The use of data from only one of the three hospitals in Auckland should not have caused bias as admission to hospital is based on geographical criteria and not on severity of disease. The definitions of definite myocardial infarction were different between the groups, the diagnostic criteria for the 1980-1 group being slightly more rigorous than those for the 1966-7 group and therefore selecting more severely ill patients. The degree of difference cannot be estimated but it is unlikely to have accounted for the observed changes in severity. A criterion for entry to the study was survival at four weeks after the onset of myocardial infarction, which could have led to a difference in severity of infarction between the groups because of changes in management and hence to a difference in the composition of the patients entering the study at the different times. Again, the effect of this change cannot be measured, although it is unlikely to have had any appreciable effect on the three year survival.

We do not know whether survival improved gradually or over a short period during the follow up as information on coronary prognostic index and three year survival was not available between the two periods of study. We have examined trends in survival over a shorter time interval (1974-81) and failed to show a significant improvement. ${ }^{+}$A Swedish study, in which the criteria for inclusion were age less than 60 , first myocardial infarction, and survival to discharge from hospital, showed an improvement in survival which may have occurred from 1968-9 to $1970-1 . .^{9}$ Our data are also consistent with this interpretation. Improved survival after myocardial infarction during $1970-80$ has also been reported in Minnesota but has been mostly attributed to improved survival in hospital. ${ }^{10}$ Severity of infarction seemed to have increased with time and hence could not explain the improved survival. As the Minnesota study began in 1970 it may possibly have missed the period when survival improved in patients alive at discharge from hospital.

The use of $\beta$ blockers increased considerably from 1966-7 to 1981-2, and coronary artery operations are now widely used for treating severe angina. Neither of these factors is, however, sufficient to explain the change in survival, particularly if the improvement occurred in the early part of the period of study. About $30 \%$ of patients discharged from hospitals in Auckland 
in 1981 were estimated to be taking $\beta$ blockers, ${ }^{11}$ but nearly all of them would have to have survived because of $\beta$ blockade for this to account solely for the increased survival rates; this is unlikely given the modest effect on survival of $\beta$ blockers taken after infarction. ${ }^{12}$ The hazards of continued smoking after myocardial infarction became widely recognised in the early $1970 \mathrm{~s},{ }^{13}$ and as the need to stop smoking now receives much more emphasis in hospital than it did in the 1960s we suspect that this may be the most important factor contributing to improved survival.

Our results suggest that an improvement in long term survival after myocardial infarction contributed to the decline in mortality from coronary heart disease in New Zealand, but there is as yet no evidence that it is continuing to do so. Further reductions in mortality from coronary heart disease are likely only if emphasis is placed on primary prevention.

We thank Dr P W T Brandt for his advice on interpreting the chest $x$ ray films and the Medical Research Council of New Zealand and the National Heart Foundation for their support of the 1981-2 study. AWS was funded by the Medical Research Council of New Zealand.
Beaglehole R, Bonita R, Jackson R, Stewart A. Cardiovascular mortality in New Zealand and Australia 1968-1983: how can the diverging trends be explained? NZ Med f 1986:99:1-3.

2 Beaglehole R, Bonita R, Jackson R, Stewart A, Sharpe N, Fraser GE. Trends in coronary heart disease event rates in New Zealand 1974-81. Am $\mathcal{J}$ Epidemiol 1984;184:225-35

3 Stewart AW, Beaglehole R, Fraser GE, Sharpe DN. Trends in survival after myocardial infarction in New Zealand 1974-81. Lancet 1984;ii:444-6.

4 Stewart AW, Beaglehole R, Fraser GE, Sharpe DN. Has the long term prognosis following myocardial infarction improved? NZ Med $\mathcal{F}$ 1986;99. $403-5$

5 Norris RM, Brandt PWT, Caughey DE, Lee AJ, Scott PJ. A new coronary prognostic index. Lancet 1969;i:274-8.

6 Norris RM, Caughey DE, Deeming LW, Mercer CJ, Scott PJ. Coronary prognostic index for predicting survival

עe 1969. (Working party report, part 2.)

8 SAS Institute. SUGI supplemental library user's guide, version 5 th ed. Cary, North Carolina: SAS Institute, 1986 .

9 Aberg A, Bergstrand R, Johansson S, et al. Declining trend in mortality after myocardial infarction. Br Heart $\mathcal{f}$ 1984;51:346-51.

10 Gomez-Marin O, Folsom AR, Kottke TE, et al. Improvement in long term survival among patients hospitalized with acute myocardial infarction, 1970 to 1980. N Engl f Med 1987;316:1353-9.

11 Beaglehole R. Medical management and the decline in mortality from coronary heart disease. Br Med J 1986;292:33-5.

12 Barber NS, Lewis JA. Confidence in results of beta-blocker post infarction trends. BrMed $\mathcal{7}$ 1982;285:1749-50

13 Wilhelmsson C, Vedin JA, Elmfeldt D, Tibblin G, Wilhelmsen L. Smoking and myocardial infarction. Lancet $1975 ;$; $415-20$.

(Accepted 20 May 1988)

\title{
Postmenopausal oestrogen treatment and stroke: a prospective study
}

\author{
Annlia Paganini-Hill, Ronald K Ross, Brian E Henderson
}

\section{Abstract}

Study objective-To determine whether postmenopausal oestrogen use affects the risk of dying from stroke.

Design-Postal questionnaire survey to elicit details of oestrogen replacement therapy and potential risk modifiers.

Setting-Californian retirement community.

Participants-All 22781 residents of community (white, affluent, well educated) contacted by mail and phone; $13986(61 \%$, median age 73$)$ responded, including $\mathbf{8 8 8 2}$ women. These formed cohort for mortality follow up, using health department death certification. Only 13 lost to follow up, apparently not deceased, but 34 excluded because no information on oestrogen use.

Interventions-None.

End point-Mortality rate from stroke compared in women who did and did not receive oestrogen replacement treatment.

Measurements and main results-Age adjusted mortality rates were computed using internal standard and four age groups. By January 1987 there had been 1019 deaths in the cohort. Twenty out of 4962 women who used oestrogen replacement treatment died from stroke compared with 43 out of 3845 women who did not use oestrogen replacement treatment: relative risk $0.53,95 \%$ confidence interval 0.31 to 0.91 . Protection was found in all age groups except the youngest and was unaffected by adjustment for possible confounding factors (hypertension, smoking, alcohol, body mass index, exercise)

Conclusions-Oestrogen replacement treatment protects against death due to stroke.

\section{Introduction}

Although mortality rates are declining, stroke continues to be the third leading cause of death in the
United States after heart disease and cancer ${ }^{1}$ as well as a major contributor to disability. Since stroke is often fatal and the impact of treatment on prognosis is limited, control of the disease must be through primary prevention.

Recent cohort and case-control studies have suggested that the use of oestrogen replacement treatment by postmenopausal women protects against death and admission to hospital due to cardiovascular disease. ${ }^{2 \cdot 15}$ As some of the major risk factors for heart disease are also risk factors for stroke, we examined the association of postmenopausal hormone use and stroke in a prospective study conducted in a retirement community in southern California. The study design provided the opportunity of obtaining details on potential risk modifiers, such as prior heart disease, hypertension, cigarette smoking, alcohol intake, exercise, and weight, as well as on the dose and duration of use of oestrogens.

\section{Methods}

In June 1981 a health questionnaire was mailed to all residents of Leisure World, Laguna Hills, a retirement community near Los Angeles, California. New residents who moved into the community after this date were mailed the questionnaire in June 1982, June 1983, and October 1985. Residents of this community are almost entirely white, moderately affluent, and well educated. The residents' median age was 73 at the time of the initial mailing, and about two thirds were women. After three mailings and follow up telephone contact $13986(61 \%)$ of the 22781 residents returned questionnaires; 8882 of these respondents were women

The health questionnaire requested information on certain medical diagnoses including stroke, angina, myocardial infarction, and hypertension; height and weight; consumption of cigarettes and alcohol; and, for women, menstrual and reproductive events, including gynaecological operations. Detailed information was collected on the use of oestrogens during the meno- 